\title{
Synthesis and emerging frontiers in social-ecological systems research methods
}

Maja Schlüter, ${ }^{1}$ Reinette Biggs, ${ }^{1,2}$ Hayley Clements, ${ }^{2}$ Alta de Vos, ${ }^{3}$ Kristine Maciejewski ${ }^{2}$ and Rika Preiser ${ }^{2}$

${ }^{1}$ STOCKHOLM RESILIENCE CENTRE, STOCKHOLM UNIVERSITY, STOCKHOLM, SWEDEN ${ }^{2}$ CENTRE FOR SUSTAINABILITY TRANSITIONS, STELLENBOSCH UNIVERSITY, STELLENBOSCH, SOUTH AFRICA ${ }^{3}$ DEPARTMENT OF ENVIRONMENTAL SCIENCE, RHODES UNIVERSITY, MAKHANDA, SOUTH AFRICA

\section{Introduction}

Social-ecological systems (SES) research is a rapidly emerging new research domain within the broader emerging area of sustainability science. It is largely a problem-driven and action-oriented field, motivated by the immense sustainability and equity-related challenges facing society (see Chapter 1). Social-ecological systems research is based on an understanding that SES are complex adaptive systems (CAS), where social and ecological dynamics are deeply intertwined, and give rise to features and problems that cannot be understood or addressed by studying these dimensions in isolation (see Chapter 2). The field draws on and combines methods from both natural and social sciences, and combines quantitative and qualitative approaches. As such, SES research is characterised by epistemological and methodological pluralism, which is challenging for those entering the field and has complex implications for the research process, methods and ethical considerations to be taken into account in SES research (see Chapter 3).

This book aims to clarify and synthesise this plurality by providing an introduction to SES research (Part 1), and the diversity of methods currently used in the field (Part 2). The aim of this final chapter (Part 3) is to provide a synthesis of the current landscape of SES methods, critically reflect on the methods with respect to their ability to address systemic features of SES and discuss some of the most common methodological challenges associated with the complex adaptive and intertwined nature of SES. Based on this synthesis, we identify methodological gaps and discuss novel methods and method combinations that may help to address these gaps and move the field forward.

\section{The current landscape of SES methods}

Building on the summaries at the start of each chapter in Part 2, this section presents patterns of method characteristics and systemic features found across the set of methods presented in this book. Although we had multiple rounds of discussion with authors to identify the key characteristics of the methods and the systemic features they most commonly address, it is 
important to note that these assessments remain somewhat subjective and could potentially be interpreted in other ways. The synthesis presented here is thus intended to identify broad trends, but not to draw specific conclusions with respect to individual methods. In addition, while we refer to 'methods' in the summary matrices (Tables 33.1 and 33.2) and in the text, most chapters (and thus rows in the matrices) include multiple methods, which may differ in their key characteristics and abilities. As such, a key characteristic may be reflective of a specific method in a chapter, and not of all methods in that chapter.

\section{Synthesis of key characteristics of SES methods}

Each method or method group was characterised at the beginning of a chapter according to key dimensions such as the type of knowledge it generates, its purpose, and the spatial and temporal scales commonly addressed. Looking across the methods discussed in this book, there are more groups of methods originating from and grounded in analytical or objective research approaches than in subjective or collaborative approaches (Table 33.1). There are, however, also many methods that are based on and allow for subjective and collaborative approaches. Some methods can be applied in different ways depending on the purpose and research question, which explains why they are suited to multiple approaches. The higher frequency of analytical approaches may be a result of early SES work coming more from the natural sciences, particularly ecology and geography, using established methods in those fields (Janssen et al. 2006). Participatory approaches and co-production of knowledge and action are more recent developments connected to the challenge of linking knowledge to action in contexts where decision stakes and uncertainty are high, and knowledge is diverse and contested (Wyborn et al. 2019; Caniglia et al. 2020; Norström et al. 2020). The abundance of co-production methods is in line with a growing movement away from expert-driven knowledge to community/stakeholder knowledge and the aim to ensure the societal relevance of research. In addition to developing their own novel methods, collaborative methods often build on methods that were originally developed for analytical purposes, such as scenario development or agent-based modelling.

Social-ecological systems research methods are most commonly used for exploratory research, with explanatory and descriptive knowledge also being common knowledge types. Many methods are used for more than one of these knowledge types. The abundance of methods for exploratory and descriptive research may be because SES research works with systems where the linkages between social and ecological systems and the resulting system behaviour are highly uncertain or unknown and, contrary to established disciplines, there is little existing knowledge or theory to draw on. Much SES research, particularly in the initial years, has been frontier work. Exploratory methods allow for making connections that have not been made before, and better accounting for the complexity of SES by being less restrictive in a priori defining what is in focus. Finally, exploratory methods are very suitable for informing or being applied in processes of knowledge co-production or effecting change because they allow for working with different understandings of a system. One can, for example, use different framings or assumptions to explore the possible effects of a management measure using dynamical systems modelling or a scenario analysis method.

Different methods may be based on different theories of change, i.e. their use is based on different views about how to effect change in SES. Whereas there are many methods that are used in SES research for the broader purpose of policy and decision support, only few of them generate prescriptive knowledge, such as optimal management strategies (e.g. spatial mapping and analysis, decision analysis based on optimisation). To some extent this may be 
due to the history of the field and the focus on exploration described above, but it may also be partly due to the inherent, irreducible uncertainty of SES (Polasky et al. 2011; Nuno, Bunnefeld, and Milner-Gulland 2014). Understanding SES as complex adaptive systems entails acknowledging that outcomes of interventions cannot be fully predicted and that uncertainty is an inherent aspect of SES. The reason for this is that SES interactions are always embedded in and shaped by temporal and spatial contexts. The best we can do is therefore to explore different possibilities for the evolution of SES under different conditions. Methods for knowledge co-production and methods such as modelling and scenario planning are particularly useful in this regard because they enable us to explore the range of possible outcomes and the uncertainty associated with them, and provide insight into processes that influence the emergence of different pathways. Based on analyses of this nature, we can make 'judicious suggestions' about potential actions and policies to influence SES outcomes, but cannot offer blueprint-type procedures for ensuring specific SES outcomes (Boulton, Allen, and Bowman 2015). The large number of methods that are used for the purpose of policy/decision support while not aiming at prescription indicates that methods are often used to enhance understanding of the features and processes of SES with the aim to provide valuable insights that can inform management and governance.

Some methods can be used for multiple purposes when applied in different ways. Scenario development in global assessments, for example, is used to integrate different models and data to develop policy recommendations (Kok et al. 2017; Rosa et al. 2017). Local-scale scenarios often involve participatory processes that are used to enhance stakeholder engagement and legitimacy in decision-making (Oteros-Rozas et al. 2015). Dynamical systems, agent-based modelling and state-and-transition modelling can be used for system understanding, stakeholder engagement or policy support. The purpose of applying these methods will, however, influence who is involved in model design, analysis and interpretation, and the processes used to specify the research question, determine the model structure, validate the model and interpret results.

Since SES researchers are often interested in understanding or effecting change over time, time is an important factor. Studying change over time and the temporal characteristics of SES is, however, challenging, as we can also see in the analysis of systemic features of SES (see the next section). In terms of temporal dimensions, most methods are primarily used to study the present or recent past, and only five methods are typically used to research the 'deep' (i.e. pre-industrial) past. Whereas this can to some extent be an artefact of how methods were grouped in our analysis, it possibly reflects that SES research focuses more on the present and the future than the past. This focus may to some extent be explained by the urgency of pressing sustainability problems and the rapid changes the world experiences that direct focus to the now and the future.

The majority of methods can be used in a spatially explicit way, although this is not always done. In terms of spatial scales, all methods are appropriate and typically used for local-scale research, with many also appropriate for research across multiple places. Fewer methods are appropriate for regional- and particularly global-scale research. This may be indicative of a focus of SES research on the local scale, with studies focusing on larger-scale SES processes and dynamics only increasing in recent years. To date, there are few methods for measuring and analysing how local-scale processes affect the global level and vice versa, i.e. for exploring cross-scale processes. This may be related to a lack of conceptual frameworks and theories to address cross-scale interactions, which is an area of active SES research (e.g. the telecoupling framework (Liu et al. 2018)). Table 33.1 provides a summary of the key characteristics of the methods covered in Part 2 of the handbook. 
Maja Schlüter et al.

Table 33.1 Summary of the key characteristics of the methods covered in Part 2 of the handbook

\begin{tabular}{|c|c|c|c|c|c|c|c|c|c|c|c|c|c|c|c|c|c|c|c|c|}
\hline \multicolumn{3}{|c|}{$\begin{array}{l}\text { Research } \\
\text { approach }\end{array}$} & \multicolumn{4}{|c|}{$\begin{array}{l}\text { Knowledge } \\
\text { type }\end{array}$} & \multicolumn{4}{|c|}{$\begin{array}{c}\text { Purpose of } \\
\text { method }\end{array}$} & \multicolumn{4}{|c|}{$\begin{array}{l}\text { Temporal } \\
\text { dimension }\end{array}$} & \multicolumn{6}{|c|}{ Spatial dimension } \\
\hline 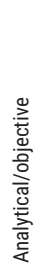 & 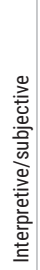 & 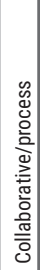 & 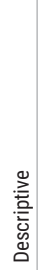 & 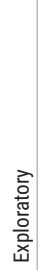 & 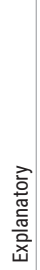 & 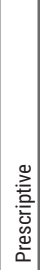 & 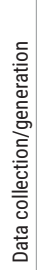 & 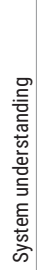 & 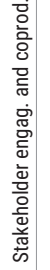 & 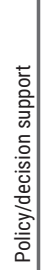 & 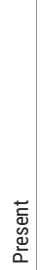 & 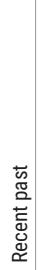 & 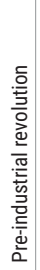 & 总 & 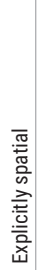 & 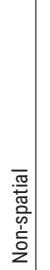 & $\begin{array}{l}\overline{\mathscr{J}} \\
\end{array}$ & 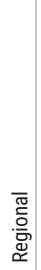 & $\begin{array}{l}\overline{\widetilde{J}} \\
\frac{\mathrm{O}}{\mathrm{O}}\end{array}$ & 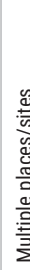 \\
\hline
\end{tabular}

METHODS FOR DATA GENERATION AND SYSTEMS SCOPING

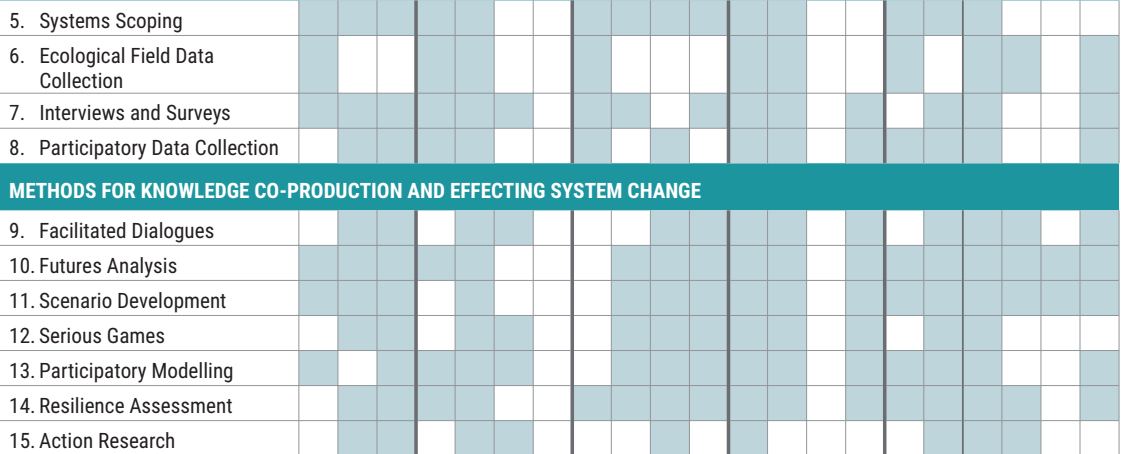

15. Action Research

METHODS FOR ANALYSING SYSTEMS - System components and linkages

16. Expert Modelling
$\begin{aligned} & \text { 17. Data Mining and Pattern } \\ & \text { Recognition }\end{aligned}$
18. Statistical Analysis
19. Qualitative Content Analysis
$\begin{aligned} & \text { 20. Comparative Case Study } \\ & \text { Analysis }\end{aligned}$
$\begin{aligned} & \text { 21. Controlled Behavioural } \\ & \text { Experiments }\end{aligned}$
22. Institutional Analysis
23. Network Analysis
24. Spatial Mapping and
Analysis

METHODS FOR ANALYSING SYSTEMS - System dynamics

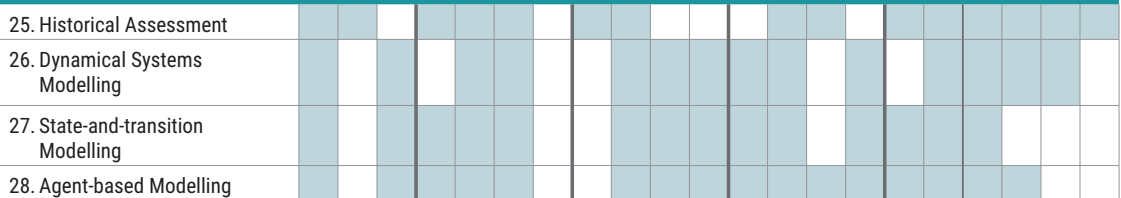

28. Agent-based Modelling

METHODS FOR ANALYSING SYSTEMS - Directly informing decision-making

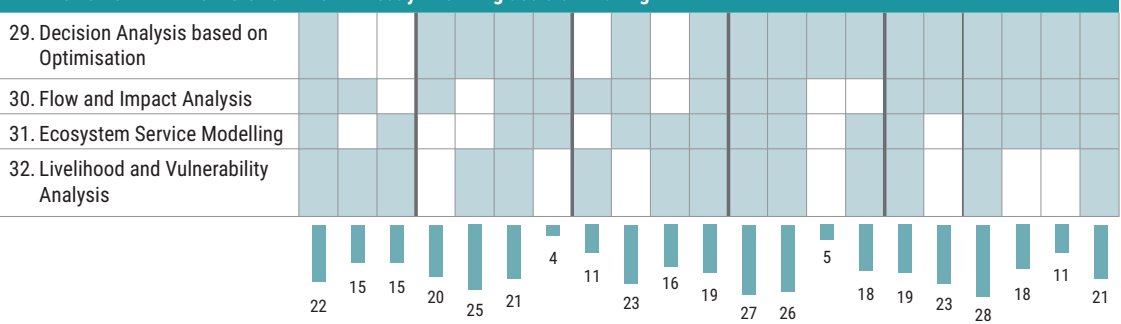




\section{Ability of methods to address different systemic features of SES}

The methods discussed in this book have different abilities when it comes to investigating systemic features of SES, but some features are more frequently addressed than others (Table 33.2). The fact that a method has not been selected for a particular feature does not, however, mean that it is not potentially suitable for addressing that feature. Expanding the scope of a method beyond its current use is in some cases an interesting method frontier (see Section 'Methodological gaps and frontiers').

There are many methods for capturing system components and one-way interactions (e.g. social-ecological components, diversity, social-ecological dependence), with far fewer methods capable of capturing processes and dynamics over time (e.g. path dependence, adaptation and self-organisation), or multiple scales and the interactions of these scales. A few methods address multiple SES features. These are often methods that have been developed more recently, specifically for studying or effecting change in complex adaptive systems (e.g. agent-based modelling, network analysis). By contrast, other methods are particularly good at addressing only a few selected features (e.g. institutional analysis and comparative case study analysis, both particularly suited to understanding and explaining collective action). Just because a method only captures a few systemic features does not mean it is a poor method for SES research. Conversely, a highly flexible method that can be used to study or support many different SES features or processes may not necessarily always be the best method for a specific feature or process. It is important to consider the limitations of methods, in terms of not only what they can capture on their own but also where several methods are needed in combination to capture different SES features.

Most methods that address system dynamics are either co-production methods (such as scenario and futures analysis) or modelling approaches, with the exception of historical profiling and methods that include time-series analysis such as spatial mapping and analysis. One of the reasons for the dominance of modelling and co-production methods in the study of SES dynamics is probably the difficulty of collecting data and analysing processes over time in empirical studies. Co-production methods are, not surprisingly, the go-to method for social learning and for facilitating processes of transformation. In contrast, collective action and collaborative governance are both addressed by co-production and by systems analysis methods, reflecting different aims: supporting processes of collective action and governance versus studying the factors and conditions that enable collective action.

Classical decision-support tools are most often used for addressing social-ecological dependence and informing policy options, but several features are consistently overlooked by this group of methods, including power relations, uncertainty, path dependence, social learning and collective action. Our analysis also suggests that methods that focus on analysing system components and linkages are more likely to address power relations, but are not suitable for understanding path dependency. Methods that analyse system dynamics, while able to address the role of power, rarely do so, but are among the few methods that address path dependency. Generally, methods used for analysing systems are not listed as methods of choice for exploring or supporting social learning or transformation, although some methods (e.g. modelling approaches) are often used in participatory processes with the aim to support social learning and transformation (see Chapter 13: Participatory modelling). 
Maja Schlüter et al.

Table 33.2 Summary of the systemic features that methods covered in Part 2 of the handbook most commonly address

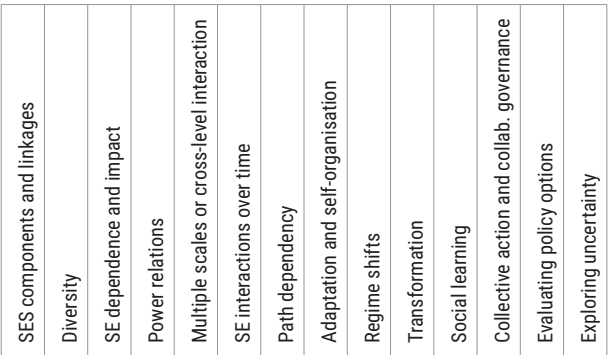

METHODS FOR DATA GENERATION AND SYSTEMS SCOPING

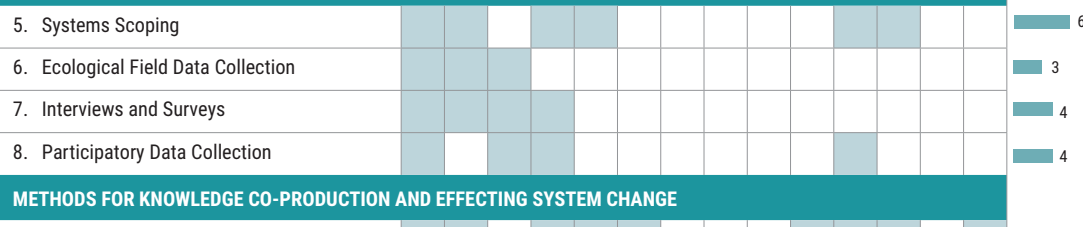

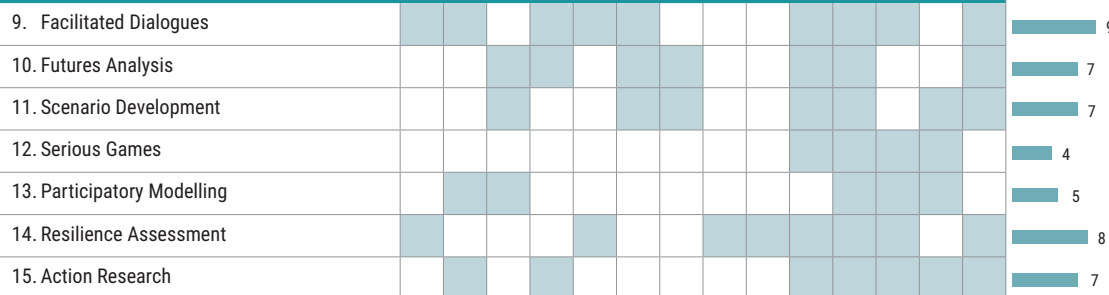

METHODS FOR ANALYSING SYSTEMS - System components and linkages

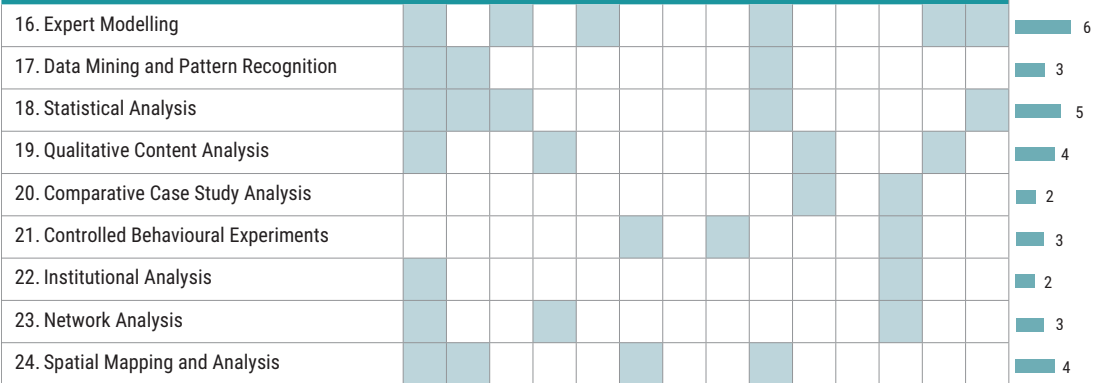

METHODS FOR ANALYSING SYSTEMS - System dynamics

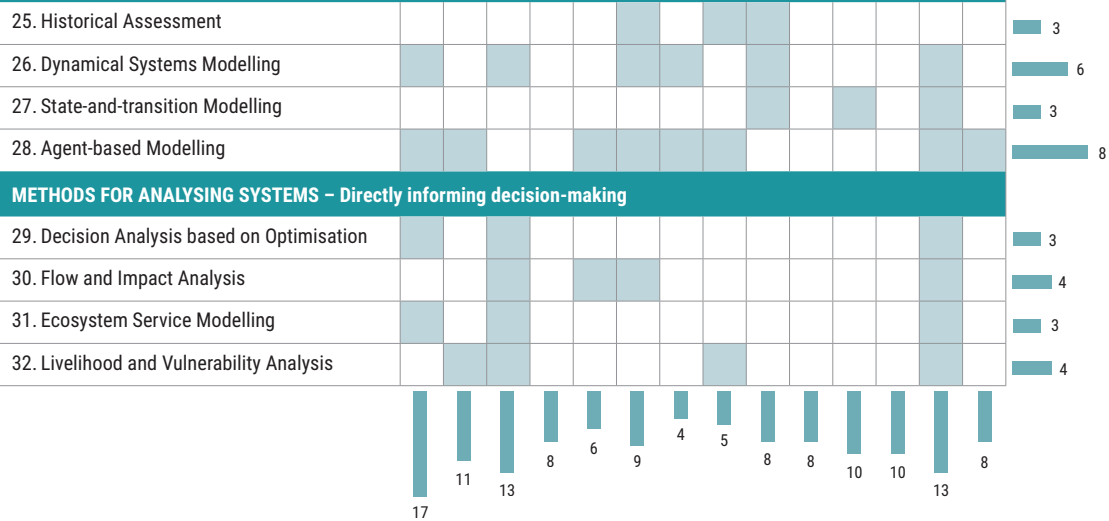




\section{Methodological challenges and practical limitations of current SES methods}

Analysing or engaging with SES that are characterised by features of complexity and social-ecological intertwinedness poses considerable methodological challenges (Chapter 2). Each method or method group has different strengths and limitations which are discussed individually in the chapters of Part 2. Here we reflect on difficulties and challenges that cut across methods and method applications. We also summarise some of the most common practical difficulties that researchers should consider when planning to use a particular method.

\section{Conceptual and methodological challenges of doing SES research}

Many of the methods presented in this handbook have their roots in disciplines whose conceptual foundations may not align with those of SES research. Methods adopted from disciplines such as ecology, economics, anthropology and geography may have been developed for different questions and purposes than those common to SES research, and may be based on assumptions and worldviews that are not compatible with a view of SES as intertwined complex adaptive systems. Methods that are based on worldviews that assume linear causation, stability or independent, fully rational actors, for instance, may be problematic, particularly when their applicability and the validity of results depend on whether these underlying assumptions hold (Ferraro, Sanchirico, and Smith 2019). There can also be a mismatch between a chosen conceptual approach and the way methods are applied to operationalise it. An example is the concept of 'ecosystem services'. Although the concept itself is grounded in an intertwined view of people and nature (Fischer and Eastwood 2016), some ecosystem service models (Chapter 31) are strongly rooted in reductionist economic assumptions, which goes against the worldviews of many communities and cultures and that of SES as intertwined complex adaptive systems (Gómez-Baggethun and Ruiz-Pérez 2011; Lele et al. 2013; Díaz et al. 2015). Such methods are still useful for SES research, but their limitations and fit with a particular research question or transdisciplinary activity, and the consequences of their use, need to be carefully considered (Jahn, Bergmann, and Keil 2012; Popa, Guillermin, and Dedeurwaerdere 2015; Popa and Guillermin 2017). Below we discuss five common challenges of dealing with the complex adaptive and social-ecological intertwined nature of SES highlighted in the method chapters in Part 2.

1. Defining system boundaries for an analysis or activity: The radically open nature of SES means that there is no objectively real 'inside' and 'outside' the system (see Chapter 2). Nevertheless, when studying or effecting change in a complex system, one needs to make choices about what or whom to include and at what level or scale. Choices about where to draw the system 'boundary' are not always obvious (Preiser et al. 2018). Often these choices are determined by the worldviews, frameworks and theories that underlie a method or method application (e.g. institutional analysis (Chapter 22)) or methodological limitations (e.g. controlled behavioural experiments (Chapter 21)); sometimes they stem from the experience and intuition of those involved in applying the method (e.g. agent-based modelling (Chapter 28)), or are co-constructed by a group of researchers and/or stakeholders (e.g. participatory modelling (Chapter 13)). In this context, it becomes critical to be transparent about how these choices have been made and to reflect on their possible consequences. The importance of transparency about what 
to include in defining system boundaries has been highlighted as a critical challenge in the chapters on participatory data collection (Chapter 8), ecological data collection (Chapter 6), interviews (Chapter 7), agent-based modelling (Chapter 28) and flow and impact analysis (Chapter 30).

2. Dealing with disciplinary biases and accounting for diversity of views: Many SES methods, particularly those for data generation and analysing systems, originate in a social or natural science discipline. When used within their respective discipline or field, key assumptions underlying a method are commonly known and accepted. Once a method is used outside its field of origin, however, this cannot be taken as given. In interdisciplinary contexts, transparency and reflexivity are thus critical for several reasons. First, choices made during method application can be heavily influenced by biases, histories and the contemporary context of researchers and participants (a challenge highlighted for instance in the chapters on interviews and surveys (Chapter 7) and historical assessment (Chapter 25)), as well as technical limitations of a method such as limitations in the number of variables that can be considered (see Chapter 21 on controlled behavioural experiments). Second, a researcher's framing and disciplinary lens impacts the interpretation of results (a challenge highlighted for instance by the chapters on historical assessment (Chapter 25) and scenarios (Chapter 11)). Third, results should always be evaluated in light of the assumptions underlying the analysis (highlighted in the chapter on agent-based modelling (Chapter 28)). In addition, most methods do not inherently require researchers to account for social differentiation (highlighted in the chapters on vulnerability analysis (Chapter 32) and interviews (Chapter 7)) and participatory research can be hard to conduct in a way that includes marginalised voices and non-scientific knowledge systems (highlighted in the chapters on systems scoping (Chapter 5) and participatory modelling (Chapter 13)). Drawing system boundaries and analysing results or engaging with a system is thus a profoundly ethical endeavour that requires transparency about underlying viewpoints, reflexivity, as well as careful consideration and discussion of ethical dilemmas that may arise during the research process.

3. Dealing with context dependence: Disciplines and their associated methods have different views about the relevance of contextual factors or processes for understanding, exploring or predicting SES outcomes. Social-ecological systems functions are contingent on context (Chapter 2) and these contexts are dynamic, i.e. they are shaped by and shape interactions in SES (Schill et al. 2019). Although many methods in SES research are used at the local scale and many researchers take pains to account for context, context-dependent methodological challenges are nevertheless pervasive. Moreover, given the cross-scale nature of SES, context extends beyond the local. Every process and action in an SES is embedded in and the result of a particular context, e.g. the behaviour of a resource user emerges from the individual's experiences, motivations, aims and her relations with her social-ecological environment (Kaaronen 2017; Raymond, Giusti, and Barthel 2018). The data collected in a research activity, the choices made when applying a method and the interpretations of results are similarly dependent on the context in which they were created. This challenge has been highlighted by many chapters dealing with methods such as interviews (Chapter 7), participatory data collection (Chapter 8), facilitated dialogues (Chapter 9), scenarios (Chapter 11), participatory modelling (Chapter 13), institutional analysis (Chapter 22), network analysis (Chapter 23), historical assessment 
(Chapter 25), agent-based modelling (Chapter 28) and livelihood and vulnerability analysis (Chapter 32).

4. Accounting for power relations: Being able to critically engage with often subtle and hidden power relations and how they shape our understanding of phenomena is very important in order to understand how certain groups of people or organisations ascribe value to, for example, some natural resources or certain practices, and how these meanings shape SES interactions and stewardship practices. Understanding power relations is not easy. They are often hidden because they are ingrained in the identity of a group or individual, and find expression in language forms, how we dress, what we value as important and how we make judgements about certain actions and attitudes (Foucault 1982; Bourdieu 1991). Several method chapters highlighted the challenge and lack of accounting for power relationships. Not acknowledging the role of power and politics or how power influences decisions in the research process can limit the diversity of knowledge or actors that are taken into account when conceptualising a system (highlighted by Chapter 5 on systems scoping). It may also influence the legitimacy of research. Actors who hold social, political or economic power may not always accept discussing or playing together on a level playing field (highlighted by Chapter 12 on serious games). Some methods have been criticised for not acknowledging or focusing enough on power relations in their frameworks (see Chapter 32 on livelihood and vulnerability analysis) or analysis (see Chapter 22 on institutional analysis).

In general, methods that investigate and analyse multiple genres, intertextual relationships and the tension between how structure and agency are co-constituted (Giddens 1984) are well placed to reflect on power relations. These include some of the chapters that have highlighted the lack of accounting for power relations as a key challenge (e.g. Chapter 7 on interviews and surveys; Chapter 19 on qualitative content analysis, and methods that enable the co-production of knowledge and systemic change such as Chapter 9 on facilitated dialogues, Chapter 10 on futures analysis, Chapter 13 on participatory modelling and Chapter 15 on action research). These methods, when used appropriately, provide the possibility of engaging with the stories, narratives, discourses, visions and myths that construct the ways in which people make sense and ascribe meaning to their place in this world. There is much potential, however, to expand the use of these methods for addressing power relations in SES research.

5. Dealing with complex causation: Social-ecological systems are characterised by complex causation and continuous change, which poses immense challenges for analysis and action (see Chapter 2). Few methods are able to deal with the complex interactions across spatial and temporal scales that give rise to the feedbacks, path dependencies and time lags that shape the emergent pathways and outcomes of SES. In addition, context sensitivity of social-ecological processes and the fact that agent- and system-level processes affect one another in various ways make identifying or untangling causal relationships difficult, if not impossible. Many quantitative methods for causal inference cannot deal with social-ecological feedbacks, non-linearities, emergence or multiple interacting causes, which limits their ability to address complex causation (Levin et al. 2012; Meyfroidt 2016; Preiser et al. 2018; De Vos, Biggs, and Preiser 2019). Some methods, such as narrative analysis and qualitative content analysis (Chapter 19) or facilitated dialogues (Chapter 9), are good at highlighting non-linear and cross-scale relationships. 
However, understanding how these relationships drive cause and effect or bring about emergent patterns of behaviour is a far more complex task (Levin et al. 2012; Chapter 27 on state-and-transition modelling).

Challenges of dealing with complex causation have been mentioned across many chapters (e.g. Chapter 7 on interviews and surveys, Chapter 22 on institutional analysis, Chapter 29 on decision analysis based on optimisation, Chapter 18 on statistical analysis and Chapter 26 on dynamical systems modelling). Many methods are limited by a lack of knowledge about possible causal processes and conditions that may have brought about a particular phenomenon of interest or underlie a particular problem. Some methods cannot address causality, or need to be combined with other methods to be able to do so (e.g. meta-analysis with an in-depth case study). Others, such as serious games (Chapter 12), behavioural experiments (Chapter 21), simple dynamical systems models (Chapter 26) or decision analysis (Chapter 29), can only incorporate a small set of variables and processes, which limits their ability to address complex causation. Others again can include many variables and connections (e.g. statistical methods (Chapter 18) or agent-based modelling (Chapter 28)) but run the risk of becoming a 'black box' that is difficult to analyse, validate and communicate. Similar to other choices during a research process, the way researchers study causation in SES is influenced by the purpose of a study (e.g. to understand, explain or predict), researchers' interests and backgrounds, and also practical considerations. A researcher who aims to provide policy support may, for instance, focus on those causes that can be manipulated and try to assess their effect on outcomes. The challenge is then to understand how these causes play out within the broader network of SES relations.

\section{Practical limitations and resource challenges}

In addition to significant conceptual and methodological challenges, most SES research also faces significant practical and resource limitations. Social-ecological systems research can be more time intensive than disciplinary research: it takes time to develop a complex adaptive systems mindset within a research team or a group of stakeholders, and many of the methods used in knowledge co-production processes require time-consuming trust-building and iterative engagement processes (Lang et al. 2012; Angelstam et al. 2013; Norström et al. 2020). Much SES research is carried out in collaborative endeavours, often across disciplines and knowledge systems, which requires openness, epistemological agility (Haider et al. 2018), communication and facilitation skills. Unfortunately, existing funding and institutional contexts are often not conducive to the collaborative research and action processes needed in SES research. It can be difficult to find funding for the longer project durations needed in inter- or transdisciplinary projects; proposals are too often still categorised and judged within disciplinary silos, and it may be difficult to recruit and train students and early career researchers because of (disciplinary) constraints within the educational system.

Furthermore, many methods require advanced technical skills, such as statistical, programming and modelling skills or facilitation experience. This is particularly challenging when methods are combined and a researcher or team needs to acquire multiple skills that might be quite diverse. When combining ethnographic research with agent-based modelling, for instance, the researcher will need to be able to engage with the rich details of a particular context while at the same time abstracting this rich knowledge into a model. Another critical issue is data availability and quality. Obtaining data on social and 
ecological aspects at comparable and relevant spatial and temporal scales can be challenging (see Chapter 30 on flow and impact analysis), which limits the integration of different datasets (e.g. scenarios). Poor quality and availability of data may also limit the extent to which certain modelling approaches can be used and accepted by non-modellers (see Chapter 27 on state-and-transition modelling). Existing datasets or mined data may also not be representative of the population of interest (see Chapter 17 on data mining and pattern recognition; Chapter 18 on statistical analysis; Chapter 24 on spatial mapping and analysis). Data availability is particularly problematic for studies of change over time, such as dynamic models and historical analyses, and studies that need spatially explicit data (see Chapter 24 on spatial mapping and analysis).

\section{Methodological gaps and frontiers}

The above synthesis highlights the diversity of methods used in SES research today. In general, methods that aim to support policy or action are well represented. There are many methods that are well suited to exploration of the present and future of SES at local scales and that can support stakeholder engagement and knowledge co-production. Whereas the majority of methods are used to study interactions within one scale, there are fewer methods for studying dynamics and cross-scale interactions. Our synthesis also highlights methodological challenges rooted in the complex, adaptive and social-ecologically intertwined nature of SES, such as accounting for social-ecological feedbacks, emergence and complex dynamics that push many traditional methods to their limits.

In this section, we highlight methodological gaps related to addressing key features of SES and to supporting the SES research approach, co-production processes and knowledge synthesis. We present ways to address these gaps and point towards some emerging methods and methodological frontiers in the field. Social-ecological systems research is a rather young, interdisciplinary field. The development of novel methods, the use of existing methods in novel ways, the introduction of methods from other disciplines and the development of new combinations of methods all present exciting ongoing research frontiers.

\section{Methods that account for emergence, cross-scale interactions and social-ecological intertwinedness}

\section{Methods for understanding and navigating emergence}

Social-ecological systems research has relatively few methods to study the complex and intertwined social-ecological processes that give rise to emergent novel properties, phenomena or behaviours of SES or to foster the capacity to navigate them. In particular, there are few methods to identify and study how the system unfolds over time and how its pathway is shaped by local adaptations, non-linear feedbacks, path dependencies and chance. The capacity to appreciate and navigate emergence is essential for transformation because it allows identifying different kinds of opportunities based on an improved understanding of complex dynamics and ways to deal with unpredictability, uncontrollability and contestation (Moore et al. 2018).

A number of methods go some way towards addressing complex dynamics and unfolding processes, but there is much potential for further development. Case study research has been instrumental in developing narratives of how transformations succeed through the cross-scale interactions of actors, networks and structural features of an SES (e.g. Gelcich et al. 2010; 
Moore et al. 2014; Herrfahrdt-Pähle et al. 2020). Network analysis, a method most commonly associated with providing a snapshot in time, can also be used to capture dynamism through time (Ryan and D'Angelo 2018), or to look at multiple time periods (Yletyinen et al. 2018; Zhao et al. 2018). Combinations of network approaches with agent-based modelling are a promising method frontier for understanding how the interplay of structure and agency influences system-level outcomes, such as the effects of a conservation intervention (Dobson et al. 2019). Dynamic modelling approaches are in general well suited to studying change of SES over time, but their potential for studying transient dynamics, coevolution and processes of emergence has not yet been fully realised. On the empirical side, process tracing (Beach and Pedersen 2013) is gaining attention as a method to study the historical processes that may have produced an outcome of interest, such as a trap (Boonstra and De Boer 2014) or an environmental policy (Orach, Schlüter, and Österblom 2017). New advances have also been proposed to better understand the coevolution of institutions and SES, such as the combined IAD-SES framework, the institutional grammar tool and the power of polycentric governance approach (Epstein et al. 2020). Finally, long-term social-ecological research sites may provide time series of social-ecological processes that will help understand patterns of dynamic interactions and their effects on the SES (Bretagnolle et al. 2019).

The conceptual and methodological challenges of emergence and complex causality have recently received attention in various subfields of sustainability science, such as land system science, ecological economics and Earth system science (Meyfroidt 2016; Carlson et al. 2018; Ferraro, Sanchirico, and Smith 2019; Runge et al. 2019). Novel methods such as advances in time-series analysis (convergent cross-mapping (CCM), Sugihara et al. 2012) or Bayesian score-based approaches (Chickering 2002) have been proposed for data-rich contexts. At the same time, authors highlight the need for multi-method approaches and triangulation because individual methods all have their limitations and biases that need to be carefully navigated (see Section 'Advances in multi- or mixed-methods approaches'). Statistical methods, for instance, are based on the assumption of absence of interference (i.e. the effect of manipulating one part of the system does not depend on changes in other parts of the system), which is highly unlikely in SES given social-ecological feedbacks (Ferraro, Sanchirico, and Smith 2019). Most importantly, there is always a need for expert knowledge about the system to guide interpretation of the results, and for recognising the assumptions and limitations of the method used. Beyond quantitative methods, qualitative methods can shed light on complex causal processes in individual cases. Biesbroek, Dupuis and Wellstead (2017), for instance, argue for mechanism-based approaches and the use of process tracing to unravel the complex causal mechanisms underlying adaptive governance (see an example in Sieber, Biesbroek, and De Block 2018).

\section{Methods accounting for multiple scales/levels or cross-level interactions}

Most disciplines and research fields focus on a selected level or scale, such as the individual, community or societal levels; or local, regional or global scales. The associated methods are often particularly suitable for that level or scale, and may be incompatible with others. Moreover, technical limitations may constrain the level of complexity and hence the number of levels or scales a method can address. Together, these characteristics limit the ability of methods to address multi-scale, multi-level and cross-level dynamics. It may be difficult, for example, for methods suited to studying systems at the local scale (e.g. institutional analysis (Chapter 22), livelihood and vulnerability analysis (Chapter 32)) to include cross-scale 
drivers, and most methods have difficulty accounting for dynamic interactions across scales (De Vos, Biggs, and Preiser 2019). Agent-based modelling, network analysis and GIS mapping are examples of methods that have the potential to address cross-scale interactions and are already doing so (e.g. Guerrero, Mcallister, and Wilson 2015; Maciejewski and Cumming 2016; Miyasaka et al. 2017; Lippe et al. 2019; Cumming and Dobbs 2020). In this context, multi-method approaches also become very important (see Section 'Advances in multi- or mixed-methods approaches'). The challenge of cross-scale and cross-level interactions calls for research in inter- and transdisciplinary teams that use multi-scalar entry points when collecting information while at the same time engaging in partnerships to account for emergent properties, feedbacks and non-linearities at and across scales so that various system facets can be connected to one another (Pricope et al. 2020).

\section{Methods to overcome dichotomies and account for social-ecological intertwinedness}

Whereas the need to better integrate the social and the ecological in SES research is increasingly recognised (see e.g. Fischer et al. 2015; Guerrero et al. 2018), doing so poses particularly difficult methodological challenges. As discussed in Chapter 2, conceptualising SES as co-constituted by social-ecological relations requires an ontology that does not separate social and ecological, culture and nature, subject and object (Hertz, Mancilla García, and Schlüter 2020). Methods rooted in either the social or the natural sciences are, however, often based on such dichotomies, which limit their ability to address socialecological intertwinedness. A method that requires working with distinct social and ecological entities that exist independently from one another cannot account for the creation of novel SES elements through continuously interacting social and ecological processes. The same applies to measuring SES. Indicators for biodiversity conservation and human well-being, for instance, are largely developed separately and often viewed in opposition to one another, which makes it impossible to conceive of human and ecological well-being as an interrelated system (Caillon et al. 2017). In addition, most methods are prone to focusing more on particular elements, actors or processes of SES from either the social or the ecological realm. An example is flow and impact analysis (Chapter 30). Despite having developed from both the social and the natural sciences, SES researchers performing flow and impact analysis often use methods adapted from particular disciplines (e.g. economics), which limits their ability to integrate human and ecological dimensions, or account for interdependencies in SES processes.

Attempts to overcome dichotomies range from developing a framework that puts interactions between human and non-human actors at the centre of analysis (Schlüter et al. 2019a), to the use of relational approaches (West et al. 2020), to methods such as radical empiricism that are based on process-relational ontologies (Mancilla García, Hertz, and Schlüter 2020). Process-relational approaches encourage careful questioning and rebuilding of the concepts used to study or engage with SES, thus making it possible to overcome dichotomies (Mancilla García, Hertz, and Schlüter 2020; West et al. 2020). Other fields can also be sources for ideas and concepts that help overcome dichotomies. Ecofeminism, for instance, draws on how women understand their connection with nature and uses this embodied knowledge as a motivation and justification for introducing new notions of intertwinedness, partnership, agency, care and stewardship (Merchant 2018). Contemporary scholars draw on ideas of post-humanism and new materialism in which the role and agency of humans is not elevated above the agency of non-living and transient beings. Novel notions such as 
'sympoeisis' suggest that there is a radical kind of entangled reciprocity between all living and non-living beings and that the world as such comes about because of a kind of 'making with'. As described by the leading 'multi-species' feminist, Donna Haraway (Haraway 2018), sympoeisis ascribes a kind of intertwinedness where all are ultimately connected to one another in ways that the specificity and proximity of connections matter. And it is the nature of the relations that emerge from the interactions that brings about structures and 'ways of being and becoming' in this world. Experiential methods, ritual practices, facilitating knowledge co-production and immersive practices can allow researchers and stakeholders to experience these modes of being co-constituted in a relational way, and can bring about a deeper awareness of the intertwined nature of SES as complex adaptive systems.

\section{Methods to support knowledge co-production and reflexive research processes}

\section{Arts-based and other creative approaches to support knowledge co-production}

Methods addressing the complexity of SES interactions and challenges are generally not good at offering clear-cut or rationally deduced directives about the best actions or interventions to effect desired SES changes. Sense-making processes are often the most appropriate way of initiating action in SES, and methods that allow multiple perspectives and voices to be included tend to be most effective. Methods that support knowledge co-production processes are good at facilitating these processes of joint sense-making. Many of the knowledge co-production methods discussed in this book (Chapters 9-15) are at the forefront of methodological development in this respect. These methods foster broader engagement with understanding diverse values and ethical imperatives regarding what is considered as desirable and just change.

One aspect that has recently gained increased attention is the importance of drawing on creativity as a resource for facilitating knowledge co-production and engagement processes. Both art and science provide avenues for inquiry and communication, impacting different audiences through the generation of a multiplicity of diverse narratives and modes of representation. Art has the ability to convey the complexity of SES intertwinedness in experimental and experiential mediums and platforms and can generate shifts in social perceptions and behaviours that can provide complementary pathways for SES knowledge co-production and engagement (Born and Barry 2010). Art-science collaborations provide a means for artists, scientists and societal stakeholders to discover new ways to convey their understanding of SES interactions to others, and provide an open platform to juxtapose potentially conflicting and contradictory perspectives (Galafassi et al. 2018; Paterson et al. 2020). Artscience approaches are increasingly used to inform scientific and public literacy and engagement concerning sustainability challenges (Eldred 2016; Angeler, Alvarez-Cobelas, and Sánchez-Carrillo 2018) and foster more embodied and experiential participation in socialecological research projects (see Chapter 8 on participatory data collection; Chapter 15 on action research). Novel examples include data sonification, an approach that allows converting scientific data into music (Angeler, Alvarez-Cobelas, and Sánchez-Carrillo 2018) and poetic inquiry, an approach that can encourage researcher reflexivity, disrupt hierarchies and humanise research by centring on participants' lived experience (Fernández-Giménez, Jennings, and Wilmer 2019). Another example is the use of performance, e.g. through forum theatre or role-playing games, to generate empathy, engage with a range of emotions and explore how participants can collectively find solutions to a shared problem (Brown, Seo, and Rounsevell 2019). 


\section{Methods to monitor the impact of research and action}

There are relatively few methods to assess the impacts of research and action in SES. Standard 'key performance index' appraisals do poorly when it comes to evaluating whether social learning or reflective and iterative processes of collaborative knowledge co-creation or change-making have taken place or not in an SES. Reflecting on lessons learnt and building this into futures planning is an essential part of action-oriented SES research, and monitoring and evaluation provide important data and experiences that contribute to this learning (Morris and Lawrence 2010). Monitoring, evaluation and learning (MEL) processes stimulate and capture shared learning and are particularly relevant to SES research and programmes designed with a systems orientation. RESILIM-O, a USAID-funded programme focused on building resilience in the Olifants River Basin in South Africa (AWARD 2017), for example, was based on the premise that the environmental and social challenges are complex and interdependent. The programme therefore used an evaluation approach that relied on 'systemic social learning' and 'learning together what is not yet known', through interactive, participatory and open-ended methods that included institutions at multiple levels. This meant that involvement of multiple activities and role-plays was seen as critical in assessing project outcomes. The purpose of the MEL approach in this programme included accountability, not only for the funders but for all stakeholders involved in the process of building resilience in the region - to communicate success stories and areas that need attention; to guide strategic planning on which projects should continue, change or stop; and to provide internal learning among the project partners, and external learning among development partners and external stakeholders (AWARD 2017).

\section{Methods to support reflexivity}

The importance of more reflexive modes of engaging with SES, in both research processes and knowledge co-production, has been a central theme throughout this book (see Chapters 1-3). Reflexivity is particularly important in view of multiple understandings of SES: to position one's research; to ensure consistency within one's research approach; to enable collaboration within diverse groups of scientists, practitioners or stakeholders; to make explicit and deal with biases, including understanding and communicating how one's personal biases may affect results and their interpretation; and to ensure that ethical aspects are taken into account, such as how inclusive the research is (or not) and whether diverse viewpoints have been considered. Despite the growing awareness of the need for reflexivity, there is still a lack of tools to support processes of reflexive engagement with SES. A few recent developments include a toolbox for philosophical dialogue, which is a set of questions to help identify and address philosophical disparities and commonalities across a group of researchers (Eigenbrode et al. 2007), a toolkit to elicit one's 'ologies' (seslink.org), i.e. theoretical and methodological commitments, and a heuristic tool to articulate and discuss individual research strategies (Hazard et al. 2020). Collaborative and participatory modelling are also useful tools to make explicit diverse and possibly contradicting viewpoints among scientists or among different stakeholders (Singer et al. 2017; Schlüter et al. 2019b).

\section{Methods for synthesis and theory building}

Social-ecological systems research has over the last two decades accumulated much indepth, place-based knowledge and understanding of key SES features and behaviours 
across a diversity of contexts. Synthesising this knowledge in a way that accounts for the complex adaptive systems nature of SES, particularly context dependence, radical openness and emergence, may help to provide carefully generalised knowledge to inform SES governance (Magliocca et al. 2018). Synthesis is a research approach that draws upon many sources of data, ideas, explanations and methods in order to generalise and build theory (Magliocca et al. 2018). Efforts to synthesise existing SES knowledge are, however, complicated by a lack of approaches and methods that can deal with different types of data and the diversity of concepts and methods by which they were collected (Magliocca et al. 2018; Cox et al. 2020). Both methodological pluralism and the variability of SES dynamics across different contexts make the development of generalisable knowledge to inform middle-range theories and governance difficult (see Chapter 22 on institutional analysis; Chapter 19 on qualitative content analysis; Cox 2015; Bodin et al. 2019; De Vos, Biggs, and Preiser 2019).

Despite these challenges, recent years have seen more and more research that moves towards synthesis. Databases of variables found across empirical cases are one attempt to standardise approaches across studies that facilitate synthesis and theory building (Cox et al. 2020). However, standardisation comes at the expense of being able to adapt methodologies to specific contexts (Magliocca et al. 2018). Examples of databases that have been developed to facilitate comparison and synthesis are the thresholds database (resalliance. org/tdb-database), regime shifts database (regimeshifts.org), the SESMAD database (sesmad.dartmouth.edu) and the SES library (seslibrary.asu.edu). Similarly, there are first attempts to facilitate qualitative data sharing and synthesis (Alexander et al. 2019). Synthesis and cross-case comparison are just one approach that can be used for context-sensitive generalisation and theorising. Recent methodological developments in SES research and the social sciences include archetype analysis (Oberlack et al. 2019) and combining crosscase with within-case analysis for developing typologies (Møller and Skaaning 2017). Another methodology for theory building in SES combines the development of empirical explanations of observed phenomena with agent-based modelling to test and explore possible explanations (Magliocca et al. 2015; Schlüter et al. 2019b). Through this combination, particularly when applied in an iterative and collaborative process that involves empirical researchers and modellers, different assumptions and understandings can be made explicit and their consequences explored through modelling and field research.

\section{Big data, machine learning and virtual/augmented reality}

Significant technological and analytical developments have enhanced the generation, storage, processing and analysis of large-scale biophysical and social datasets (Franklin et al. 2017; Gorelick et al. 2017; Dong et al. 2019; see Chapter 6 on ecological field data collection; Chapter 16 on expert modelling; Chapter 17 on data mining and pattern recognition; Chapter 18 on statistical analysis; Chapter 27 on state-and-transition modelling). These advances have increased data availability and understanding of global SES, particularly land systems such as forests (Hansen et al. 2013), surface water bodies (Pekel et al. 2016), urban accessibility (Weiss et al. 2018), agriculture (Tian et al. 2019) and fisheries (Kroodsma et al. 2018). Global-scale measurements of socio-economic characteristics are generally harder to derive than biophysical land cover (Dong et al. 2019), but are also expanding through, for example, crowdsourcing of social sensing data (Fritz 
et al. 2017; Zulkarnain et al. 2019) and mining of location-based social media data (Di Minin, Tenkanen, and Toivonen 2015; Jendryke et al. 2017; Chapter 17 on data mining and pattern recognition).

The use and usefulness of automatically derived data (e.g. remote sensing, automatic sensors) and big data have advanced significantly through the application of artificial intelligence and machine-learning techniques, such as deep learning (e.g. Christin, Hervet, and Lecomte 2019; see also Chapter 18 on statistical analysis; Chapter 17 on data mining and pattern recognition). These techniques allow for the synergising of datasets that could previously only be used in isolation (Jendryke et al. 2017; Christin, Hervet, and Lecomte 2019; Esch et al. 2020). Deep-learning approaches can help combine different resolutions and scales of data, or integrate social and biophysical datasets for the purpose of better understanding landscape dynamics, particularly as they relate to human activities (Dong et al. 2019; Chapter 25 on historical assessment). Deep learning is also contributing significantly to the development of complex predictive and analytical models (see Chapter 17 on data mining and pattern recognition; Chapter 18 on statistical analysis), and deep learning and historical land analyses are increasingly combined with scenario development to inform strategic planning processes (Drees and Liehr 2015; Sang 2020).

Virtual and augmented reality approaches have become popular as a way to elicit human values related to (often future) ecological conditions (see Chapter 8 on participatory data collection; Paine 2016; Smithwick et al. 2018; Smithwick et al. 2019) and to create realistic future worlds in scenario development, e.g. in planning smart cities (Jamei et al. 2017; Chapter 11 on scenario development; Chapter 10 on futures analysis). 'Experiential futures' bring a future into the real world, making it an immediate, first-hand encounter (Zaidi 2019). A related 'world building' technique that is increasingly used in scenario development is the use of science fiction prototyping to depict rich, nuanced storied futures (Merrie et al. 2018). This interplay between world building and storytelling is psychologically more compelling and realistic than an abstract futurist scenario or statistical prediction (Merrie et al. 2018; Zaidi 2019). Indeed, combining virtual and augmented reality and science fiction prototyping may blur the lines between experiential futures and science fiction (Zaidi 2019).

Whereas big data, machine learning and virtual/augmented reality approaches offer exciting opportunities for advancing our understanding of cross-scale and large-scale social-ecological dynamics, and operationalising new perspectives and solutions, their application requires thoughtful reflexivity (Gulsrud et al. 2018). As discussed briefly in Chapter 3, researchers have to take into account ethical concerns about regional and demographic representation underlying big datasets, discriminatory algorithms based on narrow training data, the exclusion of certain groups (e.g. older people) in virtual/augmented reality approaches, data ownership, and privacy concerns related to where data are sourced, and what additional personal data may be collected by high-tech devices ranging from smartphones to satellites (Di Minin, Tenkanen, and Toivonen 2015; Mittelstadt and Floridi 2016; Stahl and Wright 2018). In SES, neither risks nor opportunities are fixed, but are dynamic properties of changing internal contexts and cross-scale interactions (Gulsrud et al. 2018). These uncertainties, combined with the evolving nature of technology that has been changing human-nature relationships, human agency and cross-scale interactions in SES (Ahlborg et al. 2019), mean that SES researchers should be particularly aware of unintended consequences of using hightech methods and tools. 


\section{Advances in multi- or mixed-methods approaches}

The combination of methods in multi- and mixed-methods approaches is increasingly common in SES research (see Chapter 3 for a definition of multi- and mixed methods). Methods are combined in order to study multiple scales or cross-scale interactions, collect different types of data, integrate different perspectives or triangulate findings, to name just a few. While multi- or mixed-methods approaches are useful to overcome the limitations of individual methods and to include multiple perspectives or ways of analysing a system, they need to be applied with careful consideration of possible incompatibilities of the worldviews or theoretical foundations underlying each method (Johnson and Onwuegbuzie 2004).

In the context of data collection and analysis, methods have been combined to facilitate the collection of a broad range of information and data about a situation and to better account for differences between social and ecological data. An example is the combination of household questionnaires, participatory time lines, oral histories, focus group discussions, vegetation and wild animal surveys, and analysis of remote-sensing images to inform a livelihoods assessment (Sallu, Twyman, and Stringer 2010). In this study, the different quantitative and qualitative data collected were analysed using methods such as thematic analysis and iterative reflexivity to allow for inductive interpretation of qualitative data as well as statistical analysis of quantitative data. Furthermore, method combinations can be useful to study SES across scales. An example is the combination of remotely sensed data analyses with (spatial) participatory data collection to study ecosystem change and its relation to ecosystem services (Brown et al. 2018; Delgado-Aguilar, Hinojosa, and Schmitt 2019). Finally, multiand mixed-methods approaches allow triangulation of findings to build confidence in the results and account for limitations of individual methods (Bentley Brymer et al. 2016; Lee et al. 2019; Salomon et al. 2019).

In the context of modelling, method combinations are very common, particularly when the process of model building involves collecting and analysing empirical data, often in participatory ways (Voinov et al. 2018). Frontiers of combining empirical methods with modelling include using qualitative data/narratives to build the model structure (e.g. Lindkvist, Basurto, and Schlüter 2017), combining social network analysis (Dobson et al. 2019; Will et al. 2020) or process tracing with agent-based modelling (Orach, Duit, and Schlüter 2020). If models are constructed collaboratively, 'negotiation' processes between those who have the empirical understanding and those who develop the model can highlight gaps and differences in understanding that can then be explored with the model or further field research. Process tracing can be used to establish causal processes in SES that can be further explored through modelling. Orach, Schlüter and Österblom (2017), for example, use process tracing to identify coalition formation as a key mechanism through which environmental interest groups managed to attain their preferences in the 2013 EU Common Fisheries Policy reform. Using an agent-based model that formalised this mechanism, they could then explore how and under which conditions interest-group competition can lead to sustainable resource management (Orach, Duit, and Schlüter 2020).

Finally, the combination of different types of modelling, such as agent-based and dynamical systems modelling, allows researchers to make use of the strengths of the respective modelling approaches, such as the mathematical analysis methods available for dynamical systems modelling and the ability of agent-based modelling to represent human behaviour. An example is the combination of a system dynamics model of a lake with an agent-based 
model of a community to study the interplay between policy responses in the face of deteriorating lake conditions and the ecological dynamics of the lake (Martin and Schlüter 2015).

In the context of futures work, there is much experimentation with combining different tools and approaches. The Seeds of Good Anthropocenes (goodanthropocenes.net) initiative, for example, has developed a new bottom-up scenario methodology that combines a variety of futures tools, including the Mānoa method for detecting weak signals, futures wheels, the three horizons framework, and experiential futures to explore how local, potentially transformative social-ecological initiatives might grow and together create radically alternative futures (see Chapter 10 on futures analysis). Many SES scenario-development processes involve mixed-methods approaches, where narrative storylines are initially developed through various participatory approaches. These storylines may then be quantified using a variety of different models, with the outputs of some models serving as input into others. Model outputs are then typically discussed with a range of stakeholders, leading to adjustments of the storylines and models to ensure plausibility (see Chapter 11 on scenario development). In general, combining methods in knowledge co-production activities can allow for creativity and flexibility while at the same time grounding the research in biophysical and socio-economic realities. This was done, for example, by combining creative thinking and storytelling with quantitative modelling of drivers and trends to develop potential global futures of ecosystem change and human well-being during the Millennium Assessment.

\section{Conclusion}

Social-ecological systems research draws on a diverse set of approaches and methods to address real-world problems and effect change towards more sustainable and just futures. It has pioneered new ways of doing research, of doing research in a more socially just way, and of engaging with society to effect change towards more sustainable pathways. Social-ecological systems research provides opportunities to question established assumptions and fundamentally rethink the nature of reality and our ability to study and shape it. It acknowledges that the researcher is part of the SES (not just an outside observer) and poses important ethical questions. These developments reflect a fundamental shift from a mechanistic worldview towards a complexity perspective that views SES as intertwined complex adaptive systems. This shift has stimulated much exciting research and action that is visible in a proliferation of approaches and methods that at times can be bewildering.

The aim of this book is to help researchers navigate the emerging SES field by providing a comprehensive synthesis and guide to this diversity of methods, grounded in an understanding of SES as complex adaptive, intertwined systems. The book goes beyond a mere compilation of commonly used methods by reflecting on the challenges that a complexity perspective holds for how we conceptualise SES, choose and apply methods, produce knowledge and attempt to effect change within SES. We have grounded the methods in their conceptual foundations, assessed their suitability for addressing different systemic features and processes in SES, and reflected on their limitations. Together, this grounding and mapping of methods help to clarify what each method can do, how it relates to other methods, and the different approaches, knowledge types and purposes of application of each method. We hope that the book enables SES researchers to make informed choices about the method(s) to use for a particular purpose, research goal or activity in a given situation and to critically reflect on the use of a method. Furthermore, we hope that it will serve as a foundation for developing new methods or combining methods in useful and sensible ways. 
No single method can by itself capture all aspects of complexity and intertwinedness. Some methods are more limited in their ability to account for complexity because of their underlying epistemology. Others are more flexible or are based on a complexity perspective such as network analysis, dynamical systems modelling, agent-based modelling and the many methods for effecting system change in co-production processes. A better understanding of the conceptual foundations, strengths and limitations of approaches and methods can support an assessment of their suitability for a problem or question of interest. Furthermore, the different perspectives that characterise SES research and the different strengths and limitations of methods call for pluralist and integrative approaches that combine or contrast different methods in order to take advantage of their differing strengths and weaknesses. However, the theoretical commitments and epistemologies underlying different methods need to be navigated with care as they may involve incompatibilities.

Social-ecological systems research diverges from the tradition of the lone genius. Instead, doing research and engaging in SES is an inherently collaborative and integrative endeavour across disciplines, knowledge systems, and science and practice. This does not mean that every research endeavour is necessarily team research; however, every researcher will, most likely, engage with various understandings and methods coming from a diversity of worldviews and epistemologies. Whereas a plurality of methods is needed to deal with the complexity and intertwinedness of SES, these processes require careful engagement and communication as well as a reflexive practice of doing research and engaging with other researchers and stakeholders. Ultimately, studying SES and affecting change towards sustainability is a continuous learning process. Social-ecological systems are continuously changing, as is our understanding of them.

\section{Acknowledgements}

We would like to thank Krisztina Jónás for helping with the analysis and synthesis of the sections on limitations and future directions of each method chapter in Part 2 of the book. Our thanks also go to Laura Elsler, Blanca González-Mon, Romina Martin, Kirill Orach and Udita Sanga for comments that greatly helped improve the manuscript. Maja Schlüter received support from the European Research Council (ERC) under the European Union's Horizon 2020 research and innovation programme (grant agreement no. 682472 - MUSES). Reinette Biggs received support from the South African Research Chairs Initiative (SARChI) (grant 98766), the Guidance for Resilience in the Anthropocene: Investments for Development (GRAID) project funded by the Swedish International Development Agency (Sida) and a Young Researchers Grant from the Vetenskapsrådet in Sweden (grant 621-20145137). Hayley Clements is funded by a Jennifer Ward Oppenheimer Research Grant and Kone Foundation. Alta de Vos received support from a Rhodes University Council Grant. Rika Preiser's salary was co-funded by the Swedish International Development Agency's (Sida) GRAID and Swedbio programmes.

\section{References}

Ahlborg, H., I. Ruiz-Mercado, S. Molander, and O. Masera. 2019. 'Bringing Technology into Social-Ecological Systems Research - Motivations for a Socio-Technical-Ecological Systems Approach.' Sustainability 11(7): 2009. doi:10.3390/su11072009.

Alexander, S.M., K. Jones, N.J. Bennett, A. Budden, M. Cox, M. Crosas, E.T. Game et al. 2019. 'Qualitative Data Sharing and Synthesis for Sustainability Science.' Nature Sustainability. doi:10.1038/ s41893-019-0434-8. 
Angeler, D.G., M. Alvarez-Cobelas, and S. Sánchez-Carrillo. 2018. 'Sonifying Social-Ecological Change: A Wetland Laments Agricultural Transformation.' Ecology and Society 23(2): 20. doi:10.5751/ES-10055-230220.

Angelstam, P., K. Andersson, M. Annerstedt, R. Axelsson, M. Elbakidze, P. Garrido, P. Grahn et al. 2013. 'Solving Problems in Social-Ecological Systems: Definition, Practice and Barriers of Transdisciplinary Research.' Ambio 42(2): 254-265. doi:10.1007/s13280-012-0372-4.

AWARD (Association for Water and Rural Development). 2017. 'Monitoring, Evaluation, Reporting and Learning for the USAID RESILIM-O Programme MERL FRAMEWORK Cooperative Agreement AID-674-A-13-00008.' Hoedspruit, South Africa.

Beach, D., and R.B. Pedersen. 2013. Process-Tracing Methods: Foundations and Guidelines. Cambridge: University of Michigan Press.

Bentley Brymer, A.L., J.D. Holbrook, R.J. Niemeyer, A.A. Suazo, J.D. Wulfhorst, K.T. Vierling, B.A. Newingham, T.E. Link, and J.L. Rachlow. 2016. 'A Social-Ecological Impact Assessment for Public Lands Management: Application of a Conceptual and Methodological Framework.' Ecology and Society 21(3): 9. doi:10.5751/ES-08569-210309.

Biesbroek, R., J. Dupuis, and A. Wellstead. 2017. 'Explaining through Causal Mechanisms: Resilience and Governance of Social-Ecological Systems.' Current Opinion in Environmental Sustainability 28: 64-70. doi:10.1016/j.cosust.2017.08.007.

Bodin, Ö., S.M. Alexander, J. Baggio, M.L. Barnes, R. Berardo, G.S. Cumming, L.E. Dee et al. 2019. 'Improving Network Approaches to the Study of Complex Social-Ecological Interdependencies.' Nature Sustainability 2(7): 551-559. doi:10.1038/s41893-019-0308-0.

Boonstra, W.J., and F.W. de Boer. 2014. 'The Historical Dynamics of Social-Ecological Traps.' Ambio 43(3): 260-274. doi:10.1007/s13280-013-0419-1.

Born, G., and A. Barry. 2010. 'ART-SCIENCE: From Public Understanding to Public Experiment.' Journal of Cultural Economy 3(1): 103-119. doi:10.1080/17530351003617610.

Boulton, J.G., P.M. Allen, and C. Bowman. 2015. Embracing Complexity: Strategic Perspectives for an Age of Turbulence. Oxford: Oxford University Press. doi:10.1093/acprof:oso/9780199565252. 001.0001.

Bourdieu, P. 1991. On Symbolic Power, Language and Symbolic Power. Cambridge: Polity in association with Basil Blackwell.

Bretagnolle, V., M. Benoit, M. Bonnefond, V. Breton, J.M. Church, S. Gaba, D. Gilbert et al. 2019. 'Action-orientated Research and Framework: Insights from the French Long-Term SocialEcological Research Network.' Ecology and Society 24(3): 10. doi:10.5751/ES-10989-240310.

Brown, C., B. Seo, and M. Rounsevell. 2019. 'Societal Breakdown as an Emergent Property of LargeScale Behavioural Models of Land Use Change.' Earth System Dynamics 10(4): 809-845. doi:10.5194/ esd-10-809-2019.

Brown, M.I., T. Pearce, J. Leon, R. Sidle, and R. Wilson. 2018. 'Using Remote Sensing and Traditional Ecological Knowledge (TEK) to Understand Mangrove Change on the Maroochy River, Queensland, Australia.' Applied Geography 94: 71-83. doi:10.1016/j.apgeog.2018.03.006.

Caillon, S., G. Cullman, B. Verschuuren, and E.J. Sterling. 2017. 'Moving beyond the Human-Nature Dichotomy through Biocultural Approaches: Including Ecological Well-Being in Resilience Indicators.' Ecology and Society 22(4): 27. doi:10.5751/ES-09746-220427.

Caniglia, G., C. Luederitz, T. von Wirth, I. Fazey, B. Martín-López, K. Hondrila, A. König et al. 2020. 'A Pluralistic and Integrated Approach to Action-oriented Knowledge for Sustainability.' Nature Sustainability. doi:10.1038/s41893-020-00616-z.

Carlson, A., J. Zaehringer, R. Garrett, R. Felipe Bicudo Silva, P. Furumo, A. Raya Rey, A. Torres, M. Gon Chung, Y. Li, and J. Liu. 2018. 'Toward Rigorous Telecoupling Causal Attribution: A Systematic Review and Typology.' Sustainability 10(12): 4426. doi:10.3390/su10124426.

Chickering, D.M. 2002. 'Learning Equivalence Classes of Bayesian-network Structures.' Journal of Machine Learning Research 2: 445-498.

Christin, S., É. Hervet, and N. Lecomte. 2019. 'Applications for Deep Learning in Ecology.' Methods in Ecology and Evolution 10(10): 1632-1644. doi:10.1111/2041-210X.13256.

Cox, M. 2015. 'A Basic Guide for Empirical Environmental Social Science.' Ecology and Society 20(1): 63. doi:10.5751/ES-07400-200163.

Cox, M., S. Villamayor-Tomas, N.C. Ban, G. Epstein, L. Evans, F. Fleischman, M. Nenadovic et al. 2020. 'From Concepts to Comparisons: A Resource for Diagnosis and Measurement in SocialEcological Systems.' Environmental Science E Policy 107: 211-216. 
Cumming, G.S., and K.A. Dobbs. 2020. 'Quantifying Social-Ecological Scale Mismatches Suggests People Should Be Managed at Broader Scales Than Ecosystems.' One Earth 3(2): 251-259. doi:10.1016/j.oneear.2020.07.007.

Delgado-Aguilar, M.J., L. Hinojosa, and C.B. Schmitt. 2019. 'Combining Remote Sensing Techniques and Participatory Mapping to Understand the Relations between Forest Degradation and Ecosystems Services in a Tropical Rainforest.' Applied Geography 104: 65-74. doi:10.1016/j. apgeog.2019.02.003.

De Vos, A., R. Biggs, and R. Preiser. 2019. 'Methods for Understanding Social-Ecological Systems: A Review of Place-Based Studies.' Ecology and Society 24(4): 16. doi:10.5751/ES-11236-240416.

Di Minin, E., H. Tenkanen, and T. Toivonen. 2015. 'Prospects and Challenges for Social Media Data in Conservation Science.' Frontiers in Environmental Science 3. doi:10.3389/fenvs.2015.00063.

Díaz, S., S. Demissew, J. Carabias, C. Joly, M. Lonsdale, N. Ash, A. Larigauderie et al. 2015. 'The IPBES Conceptual Framework - Connecting Nature and People.' Current Opinion in Environmental Sustainability 14: 1-16. doi:10.1016/j.cosust.2014.11.002.

Dobson, A.D.M., E. de Lange, A. Keane, H. Ibbett, and E.J. Milner-Gulland. 2019. 'Integrating Models of Human Behaviour between the Individual and Population Levels to Inform Conservation Interventions.' Philosophical Transactions of the Royal Society B: Biological Sciences 374(1781): 20180053. doi:10.1098/rstb.2018.0053.

Dong, J., G. Metternicht, P. Hostert, R. Fensholt, and R.R. Chowdhury. 2019. 'Remote Sensing and Geospatial Technologies in Support of a Normative Land System Science: Status and Prospects.' Current Opinion in Environmental Sustainability 38: 44-52.

Drees, L., and S. Liehr. 2015. 'Using Bayesian Belief Networks to Analyse Social-Ecological Conditions for Migration in the Sahel.' Global Environmental Change 35: 323-339. doi:10.1016/j. gloenvcha.2015.09.003.

Eigenbrode, S.D., M. O'Rourke, J.D. Wulfhorst, D.M. Althoff, C.S. Goldberg, K. Merrill, W. Morse et al. 2007. 'Employing Philosophical Dialogue in Collaborative Science.' BioScience 57(1): 55-64. doi:10.1641/B570109.

Eldred, S.M. 2016. 'Art-Science Collaborations: Change of Perspective.' Nature 537:125-126. www. nature.com/articles/nj7618-125a.

Epstein, G., T.H. Morrison, A. Lien, G.G. Gurney, D.H. Cole, M. Delaroche, S. Villamayor-Tomas, N. Ban, and M. Cox. 2020. 'Advances in Understanding the Evolution of Institutions in Complex Social-Ecological Systems.' Current Opinion in Environmental Sustainability 44: 58-66.

Esch, T., H. Asamer, F. Bachofer, J. Balhar, M. Boettcher, E. Boissier, P. d'Angelo et al. 2020. 'Digital World Meets Urban Planet - New Prospects for Evidence-Based Urban Studies Arising from Joint Exploitation of Big Earth Data, Information Technology and Shared Knowledge.' International Journal of Digital Earth 13(1): 136-157. doi:10.1080/17538947.2018.1548655.

Fernández-Giménez, M.E., L.B. Jennings, and H. Wilmer. 2019. 'Poetic Inquiry as a Research and Engagement Method in Natural Resource Science.' Society and Natural Resources 32(10): 1080-1091. doi:10.1080/08941920.2018.1486493.

Ferraro, P.J., J.N. Sanchirico, and M.D. Smith. 2019. 'Causal Inference in Coupled Human and Natural Systems.' Proceedings of the National Academy of Sciences 116(12): 5311-5318. doi:10.1073/ pnas. 1805563115 .

Fischer, A., and A. Eastwood. 2016. 'Coproduction of Ecosystem Services as Human-Nature Interactions An Analytical Framework.' Land Use Policy 52: 41-50. doi:10.1016/j.landusepol.2015.12.004.

Fischer, J., T.A. Gardner, E.M. Bennett, P. Balvanera, R. Biggs, S. Carpenter, T. Daw et al. 2015. 'Advancing Sustainability through Mainstreaming a Social-Ecological Systems Perspective.' Current Opinion in Environmental Sustainability 14: 144-149. doi:10.1016/j.cosust.2015.06.002.

Foucault, M. 1982. The Archaeology of Knowledge. New York, NY: Pantheon Books.

Franklin, J., J.M. Serra-Diaz, A.D. Syphard, and H.M. Regan. 2017. 'Big Data for Forecasting the Impacts of Global Change on Plant Communities.' Global Ecology and Biogeography 26(1): 6-17. doi:10.1111/geb.12501.

Fritz, S., L. See, C. Perger, I. McCallum, C. Schill, D. Schepaschenko, M. Duerauer et al. 2017. 'A Global Dataset of Crowdsourced Land Cover and Land Use Reference Data.' Scientific Data 4(1): 170075. doi:10.1038/sdata.2017.75.

Galafassi, D., S. Kagan, M. Milkoreit, M. Heras, C. Bilodeau, S.J. Bourke, A. Merrie, L. Guerrero, G. Pétursdóttir, and J.D. Tàbara. 2018. "'Raising the Temperature”: The Arts in a Warming Planet.' Current Opinion in Environmental Sustainability 31: 71-79. 
Gelcich, S., T.P. Hughes, P. Olsson, C. Folke, O. Defeo, M. Fernandez, S. Foale et al. 2010. 'Navigating Transformations in Governance of Chilean Marine Coastal Resources.' Proceedings of the National Academy of Sciences 107(39): 16794-16799. doi:10.1073/pnas.1012021107.

Giddens, A. 1984. The Constitution of Society. Cambridge: Polity Press.

Gómez-Baggethun, E., and M. Ruiz-Pérez. 2011. 'Economic Valuation and the Commodification of Ecosystem Services.' Progress in Physical Geography: Earth and Environment 35(5): 613-628. doi:10.1177/0309133311421708.

Gorelick, N., M. Hancher, M. Dixon, S. Ilyushchenko, D. Thau, and R. Moore. 2017. 'Google Earth Engine: Planetary-scale Geospatial Analysis for Everyone.’ doi:10.1016/j.rse.2017.06.031.

Guerrero, A.M., N.J. Bennett, K.A. Wilson, N. Carter, D. Gill, M. Mills, C.D. Ives et al. 2018. 'Achieving the Promise of Integration in Social-Ecological Research: A Review and Prospectus.' Ecology and Society 23(3): 38. doi:10.5751/ES-10232-230338.

Guerrero, A.M., R.R.J. Mcallister, and K.A. Wilson. 2015. 'Achieving Cross-Scale Collaboration for Large Scale Conservation Initiatives.' Conservation Letters 8(2): 107-117. doi:10.1111/ conl.12112.

Gulsrud, N.M., C.M. Raymond, R.L. Rutt, A.S. Olafsson, T. Plieninger, M. Sandberg, T.H. Beery, and K.I. Jönsson. 2018. "Rage against the Machine"? The Opportunities and Risks Concerning the Automation of Urban Green Infrastructure.' Landscape and Urban Planning 180: 85-92. doi:10.1016/j.landurbplan.2018.08.012.

Haider, L.J., J. Hentati-Sundberg, M. Giusti, J. Goodness, M. Hamann, V.A. Masterson, M. Meacham et al. 2018. 'The Undisciplinary Journey: Early-career Perspectives in Sustainability Science.' Sustainability Science 13(1): 191-204. doi:10.1007/s11625-017-0445-1.

Hansen, M.C., P.V. Potapov, R. Moore, M. Hancher, S.A. Turubanova, A. Tyukavina, D. Thau et al. 2013. 'High-Resolution Global Maps of 21st-Century Forest Cover Change.' Science 342(6160). http://science.sciencemag.org/content/342/6160/850.

Haraway, D. 2018. 'Staying with the Trouble for Multispecies Environmental Justice.' Dialogues in Human Geography 8(1): 102-105. doi:10.1177/2043820617739208.

Hazard, L., M. Cerf, C. Lamine, D. Magda, and P. Steyaert. 2020. 'A Tool for Reflecting on Research Stances to Support Sustainability Transitions.' Nature Sustainability 3(2): 89-95. doi:10.1038/ s41893-019-0440-x.

Herrfahrdt-Pähle, E., M. Schlüter, P. Olsson, C. Folke, S. Gelcich, and C. Pahl-Wostl. 2020. 'Sustainability Transformations: Socio-Political Shocks as Opportunities for Governance Transitions.' Global Environmental Change 63: 102097. doi:10.1016/j.gloenvcha.2020.102097.

Hertz, T., M. Mancilla García, and M. Schlüter. 2020. 'From Nouns to Verbs: How Process Ontologies Enhance Our Understanding of Social-Ecological Systems Understood as Complex Adaptive Systems.' People and Nature 2(2): 328-338. doi:10.1002/pan3.10079.

Jahn, T., M. Bergmann, and F. Keil. 2012. 'Transdisciplinarity: Between Mainstreaming and Marginalization.' Ecological Economics 79: 1-10.

Jamei, E., M. Mortimer, M. Seyedmahmoudian, B. Horan, and A. Stojcevski. 2017. 'Investigating the Role of Virtual Reality in Planning for Sustainable Smart Cities.' Sustainability 9(11): 2006. doi:10.3390/su9112006.

Janssen, M.A., M.L. Schoon, W. Ke, and K. Börner. 2006. 'Scholarly Networks on Resilience, Vulnerability and Adaptation within the Human Dimensions of Global Environmental Change.' Global Environmental Change 16(3): 240-252. doi:10.1016/j.gloenvcha.2006.04.001.

Jendryke, M., T. Balz, S.C. McClure, and M. Liao. 2017. 'Putting People in the Picture: Combining Big Location-Based Social Media Data and Remote Sensing Imagery for Enhanced Contextual Urban Information in Shanghai.' Computers, Environment and Urban Systems 62: 99-112. doi:10.1016/j. compenvurbsys.2016.10.004.

Johnson, R.B., and A.J. Onwuegbuzie. 2004. 'Mixed Methods Research: A Research Paradigm Whose Time Has Come.’ Educational Researcher 33(7): 14-26. doi:10.3102/0013189X033007014.

Kaaronen, R.O. 2017. 'Affording Sustainability: Adopting a Theory of Affordances as a Guiding Heuristic for Environmental Policy.' Frontiers in Psychology 8. doi:10.3389/fpsyg.2017.01974.

Kok, M.T.J., K. Kok, G.D. Peterson, R. Hill, J. Agard, and S.R. Carpenter. 2017. 'Biodiversity and Ecosystem Services Require IPBES to Take Novel Approach to Scenarios.' Sustainability Science 12(1): 177-181. doi:10.1007/s11625-016-0354-8.

Kroodsma, D.A., J. Mayorga, T. Hochberg, N.A. Miller, K. Boerder, F. Ferretti, A. Wilson et al. 2018. 'Tracking the Global Footprint of Fisheries.' Science 359(6378): 904-908. doi:10.1126/science.aao5646. 
Lang, D.J., A. Wiek, M. Bergmann, M. Stauffacher, P. Martens, P. Moll, M. Swilling, and C.J. Thomas. 2012. 'Transdisciplinary Research in Sustainability Science: Practice, Principles, and Challenges.' Sustainability Science 7(Supplement 1): 25-43. doi:10.1007/s11625-011-0149-x.

Lee, L.C., J. Thorley, J. Watson, M. Reid, and A.K. Salomon. 2019. 'Diverse Knowledge Systems Reveal Social-Ecological Dynamics That Inform Species Conservation Status.' Conservation Letters 12(2): e12613. doi:10.1111/conl.12613.

Lele, S., O. Springate-Baginski, R. Lakerveld, D. Deb, and P. Dash. 2013. 'Ecosystem Services: Origins, Contributions, Pitfalls, and Alternatives.' Conservation and Society 11(4): 343. doi:10.4103/ 0972-4923.125752.

Levin, S., T. Xepapadeas, A-S. Crépin, J. Norberg, A. de Zeeuw, C. Folke, T. Hughes et al. 2012. 'Social-Ecological Systems as Complex Adaptive Systems: Modeling and Policy Implications.' Environment and Development Economics 18(2): 111-132. doi:10.1017/S1355770X12000460.

Lindkvist, E., X. Basurto, and M. Schlüter. 2017. 'Micro-Level Explanations for Emergent Patterns of Self-Governance Arrangements in Small-Scale Fisheries - A Modeling Approach.' PloS One 12(4): e0175532.

Lippe, M., M. Bithell, N. Gotts, D. Natalini, P. Barbrook-Johnson, C. Giupponi, M. Hallier et al. 2019. 'Using Agent-Based Modelling to Simulate Social-Ecological Systems across Scales.' GeoInformatica 23(2): 269-98. doi:10.1007/s10707-018-00337-8.

Liu, J., Y. Dou, M. Batistella, E. Challies, T. Connor, C. Friis, J.D. Millington et al. 2018. 'Spillover Systems in a Telecoupled Anthropocene: Typology, Methods, and Governance for Global Sustainability.' Current Opinion in Environmental Sustainability 33: 58-69.

Maciejewski, K., and G.S. Cumming. 2016. 'Multi-Scale Network Analysis Shows Scale-Dependency of Significance of Individual Protected Areas for Connectivity.' Landscape Ecology 31(4): 761-774. doi:10.1007/s10980-015-0285-2.

Magliocca, N.R., E.C. Ellis, G.R.H. Allington, A. de Bremond, J. dell'Angelo, O. Mertz, P. Messerli, P. Meyfroidt, R. Seppelt, and P.H. Verburg. 2018. 'Closing Global Knowledge Gaps: Producing Generalized Knowledge from Case Studies of Social-Ecological Systems.' Global Environmental Change 50: 1-14. doi:10.1016/j.gloenvcha.2018.03.003.

Magliocca, N.R., J. van Vliet, C. Brown, T.P. Evans, T. Houet, P. Messerli, J.P. Messina et al. 2015. 'From Meta-Studies to Modeling: Using Synthesis Knowledge to Build Broadly Applicable Process-Based Land Change Models.' Environmental Modelling E Software 72: 10-20. doi:10.1016/j. envsoft.2015.06.009.

Mancilla García, M., T. Hertz, and M. Schlüter. 2020. 'Towards a Process Epistemology for the Analysis of Social-Ecological System.' Environmental Values 29(2): 221-239. doi:10.3197/0963271 19X15579936382608.

Martin, R., and M. Schlüter. 2015. 'Combining System Dynamics and Agent-Based Modeling to Analyze Social-Ecological Interactions - An Example from Modeling Restoration of a Shallow Lake.' Frontiers in Environmental Science 3. doi:10.3389/fenvs.2015.00066.

Merchant, C. 2018. Science and Nature: Past, Present, and Future. New York: Routledge.

Merrie, A., P. Keys, M. Metian, and H. Österblom. 2018. 'Radical Ocean Futures-Scenario Development Using Science Fiction Prototyping.' Futures 95: 22-32. doi:10.1016/j.futures.2017.09.005.

Meyfroidt, P. 2016. 'Approaches and Terminology for Causal Analysis in Land Systems Science.' Journal of Land Use Science 11(5): 501-522. doi:10.1080/1747423X.2015.1117530.

Mittelstadt, B.D., and L. Floridi. 2016. 'The Ethics of Big Data: Current and Foreseeable Issues in Biomedical Contexts.' Science and Engineering Ethics 22(2): 303-341.

Miyasaka, T., Q.B. Le, T. Okuro, X. Zhao, and K. Takeuchi. 2017. 'Agent-Based Modeling of Complex Social-Ecological Feedback Loops to Assess Multi-Dimensional Trade-Offs in Dryland Ecosystem Services.' Landscape Ecology 32(4): 707-727. doi:10.1007/s10980-017-0495-x.

Møller, J., and S-E. Skaaning. 2017. 'Explanatory Typologies as a Nested Strategy of Inquiry: Combining Cross-case and Within-case Analyses.' Sociological Methods \& Research 46(4): 1018-10148. doi:10.1177/0049124115613778.

Moore, M-L., P. Olsson, W. Nilsson, L. Rose, and F. Westley. 2018. 'Navigating Emergence and System Reflexivity as Key Transformative Capacities: Experiences from a Global Fellowship Program.' Ecology and Society 23(2): 38. doi:10.5751/ES-10166-230238.

Moore, M.-L., O. Tjornbo, E. Enfors, C. Knapp, J. Hodbod, J.A. Baggio, A. Norström, P. Olsson, and D. Biggs. 2014. 'Studying the Complexity of Change: Toward an Analytical Framework for Understanding Deliberate Social-Ecological Transformations.' Ecology and Society 19(4): 54. doi:10.5751/ ES-06966-190454. 
Morris, J., and A. Lawrence. 2010. 'Learning from Monitoring \& Evaluation - a Blueprint for an Adaptive Organisation.' Social \& Economic Research Group, Forest Research.

Norström, A.V., C. Cvitanovic, M.F. Löf, S. West, C. Wyborn, P. Balvanera, A.T. Bednarek et al. 2020. 'Principles for Knowledge Co-Production in Sustainability Research.' Nature Sustainability 3(3): 182-190. doi:10.1038/s41893-019-0448-2.

Nuno, A., N. Bunnefeld, and E. Milner-Gulland. 2014. 'Managing Social-Ecological Systems under Uncertainty: Implementation in the Real World.' Ecology and Society 19(2): 52. doi:10.5751/ ES-06490-190252.

Oberlack, C., D. Sietz, E. Bürgi Bonanomi, A. de Bremond, J. Dell'Angelo, K. Eisenack, E.C. Ellis et al. 2019. 'Archetype Analysis in Sustainability Research: Meanings, Motivations, and Evidence-Based Policy Making.' Ecology and Society 24(2): 26. doi:10.5751/ES-10747-240226.

Orach, K., A. Duit, and M. Schlüter. 2020. 'Sustainable Natural Resource Governance under Interest Group Competition in Policy-Making.' Nature Human Behaviour, May. doi:10.1038/s41562-020-0885-y.

Orach, K., M. Schlüter, and H. Österblom. 2017. 'Tracing a Pathway to Success: How Competing Interest Groups Influenced the 2013 EU Common Fisheries Policy Reform.' Environmental Science E Policy 76: 90-102. doi:10.1016/j.envsci.2017.06.010.

Oteros-Rozas, E., B. Martín-López, T.M. Daw, E.L. Bohensky, J.R.A. Butler, R. Hill, J. Martin-Ortega et al. 2015. 'Participatory Scenario Planning in Place-Based Social-Ecological Research: Insights and Experiences from 23 Case Studies.' Ecology and Society 20(4): 32. doi:10.5751/ ES-07985-200432.

Paine, G. 2016. 'Ecologies of Listening and Presence: Perspectives from a Practitioner.' Contemporary Music Review 35(3): 362-371. doi:10.1080/07494467.2016.1239385.

Paterson, S.K., M. le Tissier, H. Whyte, L.B. Robinson, K. Thielking, M. Ingram, and J. McCord. 2020. 'Examining the Potential of Art-Science Collaborations in the Anthropocene: A Case Study of Catching a Wave.' Frontiers in Marine Science 7: 340. doi:10.3389/fmars.2020.00340.

Pekel, J.F., A. Cottam, N. Gorelick, and A.S. Belward. 2016. 'High-Resolution Mapping of Global Surface Water and Its Long-term Changes.' Nature 540(7633): 418-422. doi:10.1038/nature20584.

Polasky, S., S.R. Carpenter, C. Folke, and B. Keeler. 2011. 'Decision-Making under Great Uncertainty: Environmental Management in an Era of Global Change.' Trends in Ecology \& Evolution 26(8): 398-404. doi:10.1016/j.tree.2011.04.007.

Popa, F., and M. Guillermin. 2017. 'Reflexive Methodological Pluralism.' Journal of Mixed Methods Research 11(1): 19-35. doi:10.1177/1558689815610250.

Popa, F., M. Guillermin, and T. Dedeurwaerdere. 2015. 'A Pragmatist Approach to Transdisciplinarity in Sustainability Research: From Complex Systems Theory to Reflexive Science.' Futures 65: 45-56. doi:10.1016/j.futures.2014.02.002.

Preiser, R., R. Biggs, A. de Vos, and C. Folke. 2018. 'Social-Ecological Systems as Complex Adaptive Systems: Organizing Principles for Advancing Research Methods and Approaches.' Ecology and Society 23(4): 46. doi:10.5751/ES-10558-230446.

Pricope, N.G., L. Cassidy, A.E. Gaughan, J.D. Salerno, F.R. Stevens, J. Hartter, M. Drake, and P. Mupeta-Muyamwa. 2020. 'Addressing Integration Challenges of Interdisciplinary Research in SocialEcological Systems.' Society \& Natural Resources 33(3): 418-431. doi:10.1080/08941920.2019.1680783.

Raymond, C.M., M. Giusti, and S. Barthel. 2018. 'An Embodied Perspective on the Co-Production of Cultural Ecosystem Services: Toward Embodied Ecosystems.' Journal of Environmental Planning and Management 61(5-6): 778-799. doi:10.1080/09640568.2017.1312300.

Rosa, I.M.D., H.M. Pereira, S. Ferrier, R. Alkemade, L.A. Acosta, H.R. Akcakaya, E. den Belder et al. 2017. 'Multiscale Scenarios for Nature Futures.' Nature Ecology \& Evolution 1(10): 1416-1419. doi:10.1038/s41559-017-0273-9.

Runge, J., S. Bathiany, E. Bollt, G. Camps-Valls, D. Coumou, E. Deyle, C. Glymour et al. 2019. 'Inferring Causation from Time Series in Earth System Sciences.' Nature Communications 10(1): 2553. doi:10.1038/s41467-019-10105-3.

Ryan, L., and A. d'Angelo. 2018. 'Changing Times: Migrants' Social Network Analysis and the Challenges of Longitudinal Research.' Social Networks 53: 148-158. doi:10.1016/j.socnet.2017.03.003.

Sallu, S.M., Twyman, C., and Stringer, LC. 2010. 'Resilient or Vulnerable Livelihoods? Assessing Livelihood Dynamics and Trajectories in Rural Botswana.' Ecology and Society 15(4): 3. www. ecologyandsociety.org/vol15/iss4/art3.

Salomon, A.K., A.E. Quinlan, G.H. Pang, D.K. Okamoto, and L. Vazquez-Vera. 2019. 'Measuring Social-Ecological Resilience Reveals Opportunities for Transforming Environmental Governance.' Ecology and Society 24(3): 16. doi:10.5751/ES-11044-240316. 
Sang, N., ed. 2020. Modelling Nature-Based Solutions: Integrating Computational and Participatory Scenario Modelling for Environmental Management and Planning. Cambridge: Cambridge University Press.

Schill, C., J.M. Anderies, T. Lindahl, C. Folke, S. Polasky, J.C. Cárdenas, A-S. Crépin, M.A. Janssen, J. Norberg, and M. Schlüter. 2019. 'A More Dynamic Understanding of Human Behaviour for the Anthropocene.' Nature Sustainability 2(12): 1075-10782. doi:10.1038/s41893-019-0419-7.

Schlüter, M., L. Haider, S. Lade, E. Lindkvist, R. Martin, K. Orach, N. Wijermans, and C. Folke. 2019a. 'Capturing Emergent Phenomena in Social-Ecological Systems: An Analytical Framework.' Ecology and Society 24(3): 11. doi:10.5751/ES-11012-240311.

Schlüter, M., K. Orach, E. Lindkvist, R. Martin, N. Wijermans, Ö. Bodin, and W.J. Boonstra. 2019b. 'Toward a Methodology for Explaining and Theorizing about Social-Ecological Phenomena.' Current Opinion in Environmental Sustainability 39: 44-53. doi:10.1016/j.cosust.2019.06.011.

Sieber, I.M., R. Biesbroek, and D. de Block. 2018. 'Mechanism-based Explanations of Impasses in the Governance of Ecosystem-based Adaptation.' Regional Environmental Change. doi:10.1007/ s10113-018-1347-1.

Singer, A., S. Gray, A. Sadler, L. Schmitt Olabisi, K. Metta, R. Wallace, M.C. Lopez, J. Introne, M. Gorman, and J. Henderson. 2017. 'Translating Community Narratives into Semi-quantitative Models to Understand the Dynamics of Socio-Environmental Crises.' Environmental Modelling E Software 97: 46-55. doi:10.1016/j.envsoft.2017.07.010.

Smithwick, E., E. Baxter, K. Kim, S. Edel-Malizia, S. Rocco, and D. Blackstock. 2018. 'Interactive Videos Enhance Learning about Socio-Ecological Systems.' Journal of Geography 117(1): 40-49. doi: 10.1080/00221341.2017.1374433.

Smithwick, E.A.H., C. Caldwell, A. Klippel, R.M. Scheller, N. Tuana, R.B. Bird, K. Keller et al. 2019. 'Learning about Forest Futures under Climate Change through Transdisciplinary Collaboration across Traditional and Western Knowledge Systems.' In Collaboration Across Boundaries for Social-Ecological Systems Science: Experiences Around the World, edited by S.G. Perz, 153-184. Cham: Palgrave Macmillan. https://link.springer.com/chapter/10.1007/978-3-030-13827-1_5.

Stahl, B.C., and D. Wright. 2018. 'Ethics and Privacy in AI and Big Data: Implementing Responsible Research and Innovation.' IEEE Security and Privacy 16(3): 26-33. doi:10.1109/MSP. 2018.2701164.

Sugihara, G., R. May, H. Ye, C-h. Hsieh, E. Deyle, M. Fogarty, and S. Munch. 2012. 'Detecting Causality in Complex Ecosystems.' Science 338(6106): 496-500. doi:10.1126/science.1227079.

Tian, S., A.I.J.M. van Dijk, P. Tregoning, and L.J. Renzullo. 2019. 'Forecasting Dryland Vegetation Condition Months in Advance through Satellite Data Assimilation.' Nature Communications 10(1): 1-7. doi:10.1038/s41467-019-08403-x.

Voinov, A., K. Jenni, S. Gray, N. Kolagani, P.D. Glynn, P. Bommel, C. Prell et al. 2018. 'Tools and Methods in Participatory Modeling: Selecting the Right Tool for the Job.' Environmental Modelling and Software 26.

Weiss, D.J., A. Nelson, H.S. Gibson, W. Temperley, S. Peedell, A. Lieber, M. Hancher et al. 2018. 'A Global Map of Travel Time to Cities to Assess Inequalities in Accessibility in 2015.' Nature 553(7688): 333-336. doi:10.1038/nature25181.

West, S., L.J. Haider, S. Stålhammar, and S. Woroniecki. 2020. 'A Relational Turn for Sustainability Science? Relational Thinking, Leverage Points and Transformations.' Ecosystems and People 16(1): 304-325. doi:10.1080/26395916.2020.1814417.

Will, M., J. Groeneveld, K. Frank, and B. Müller. 2020. 'Combining Social Network Analysis and Agent-Based Modelling to Explore Dynamics of Human Interaction: A Review.' SocioEnvironmental Systems Modelling 2: 16325. doi:10.18174/sesmo.2020a16325.

Wyborn, C., A. Datta, J. Montana, M. Ryan, P. Leith, B. Chaffin, C. Miller, and L. van Kerkhoff. 2019. 'Co-Producing Sustainability: Reordering the Governance of Science, Policy, and Practice.' Annual Review of Environment and Resources 44(1): 319-346. doi:10.1146/annurev-environ101718-033103.

Yletyinen, J., J. Hentati-Sundberg, T. Blenckner, and Ö. Bodin. 2018. 'Fishing Strategy Diversification and Fishers' Ecological Dependency.' Ecology and Society 23(3): 28. doi:10.5751/ ES-10211-230328.

Zaidi, L. 2019. 'Worldbuilding in Science Fiction, Foresight and Design.' Journal of Futures Studies 23(4) 15-26. doi:10.6531/JFS.201906_23(4).0003. 
Zhao, Y., Y. Wei, B. Wu, Z. Lu, and L. Fu. 2018. 'A Connectivity-based Assessment Framework for River Basin Ecosystem Service Management.' Current Opinion in Environmental Sustainability 33: 34-41. doi:10.1016/j.cosust.2018.03.010.

Zulkarnain, F., M.D.M. Manessa, W. Suseno, A. Ardiansyah, R. Bakhtiar, A.N. Safaryanto, B.W. Widjaja, and R. Rokhmatuloh. 2019. 'People in Pixels: Developing Remote Sensing-based Geodemographic Estimation through Volunteered Geographic Information and Crowdsourcing.' Conference Paper: Remote Sensing Technologies and Applications in Urban Environments IV. doi:10.1117/12.2533230. 